\title{
Classification Trends in Junior College Libraries
}

\begin{abstract}
A survey was made of the classification schemes employed in America junior college libraries. Of 690 institutions reporting, just over threefourths use the Dewey scheme, considerably fewer than the 96.5 per cent that reported using the DC in a similar study in 1961. Of the 159 new junior colleges established since 1961, 38.2 per cent are now using LC, manifesting a trend toward use of the latter scheme. The author proposes that professional organizations actively encourage adoption of the LC Classification scheme.
\end{abstract}

D URING the last few years many librarians have discussed the merits of the Dewey Decimal versus the Library of Congress Classification systems. The concept of centralized cataloging, although generally on the fringes of library practice for many years, is intimately connected with the present dialogue (or dispute, depending on one's perspectives or prejudices) over DC versus LC. That there is a need to rethink the entire classification picture is obvious from the glut of published material available and the increasing costs of technical processing in libraries.

An increase in interest in the LC Classification system has become apparent since 1960. Numerous articles and studies have appeared which make it reasonably clear that the application of the LC system is less costly if accepted with the spirit of centralized cataloging firmly in mind. Objective analyses of the classification problem bear out this statement. ${ }^{1}$

\footnotetext{
${ }^{1}$ It is recognized that cost studies at one institution will not necessarily be transferrable to another since wages very often fluctuate by region and area. In terms of comparative costs between the DC and
}

Mr. Taylor is Library Director in the University of Puget Sound, Tacoma.
During the last seven years junior colleges have increased throughout much of the country. A survey of classification use and trends in this developing movement in higher education seemed appropriate in order to determine the awareness and knowledgeability of junior college librarians concerning the problems of library classification.

The survey was conducted by means of a postal card form with a covering letter explaining the project. The information requested was limited to seven questions. Aside from the institutional identifications, the most important questions dealt with the classification systems used and the period the present system had been in use.

Only one previous survey ${ }^{2}$ in recent years attempted to obtain data on the classification systems used by junior college libraries. The Rowland survey covered all junior colleges listed in the "Junior College Directory, 1961"3 and

the LC systems, however, the proportional economies and advantages (in speed, uniformity, for instance) of the LC system, remain most obvious if the system is applied with the principle of standardized and centralized cataloging firmly in mind.

${ }^{2}$ Arthur Ray Rowland, "Cataloging and Classification in Junior College Libraries," Library Resources d Technical Services, VII (Summer 1963), 254-58. 3 "Junior College Directory, 1961," Junior College Journal, XXXI (January 1961), 267-302. 
obtained slightly over a 50 per cent return. The present survey covered all junior colleges listed in the 1967 Junior College Directory, ${ }^{4}$ which represented all of the fifty states, District of Columbia, Canal Zone, Puerto Rico, and Virgin Islands. Replies were received from 690 of the 837 two-year institutions listed in the directory, or slightly better than 82 per cent.

\section{Classification}

The present survey identifies by name only the Dewey and the LC Classification systems. Four junior college libraries used other classification systems. No attempt was made to identify these four systems since for all practical purposes only the Dewey and the Library of Congress systems are in widespread use in this country. Other classifications may be used by some general academic libraries and even public libraries which appear less concerned with the implications of their individualism. It is appropriate in the confines of the library school classroom to discuss theoretical aspects of various classification systems, but as a matter of pragmatic recourse, these systems are used only by those libraries who have been caught in the expensive theoretical web of their own solipsism.

Rowland's survey obtained useful information from 315 libraries and indicated that as of 1961, 96.5 per cent of junior college libraries were using Dewey with only 3.5 per cent using the $\mathrm{Li}$ brary of Congress system. The present survey indicates that there is a tendency now to prefer the Library of Congress system. Table 1 summarizes the data collected from the 690 cooperating libraries.

It is unfortunate that not all of the junior colleges listed in the 1967 direc-

41967 Junior College Directory (Washington: American Association of Junior Colleges, 1967). The directory covers the period from September 1965 to August 1966 and the fall enrollments for 1966.
TABLE 1

\begin{tabular}{l|c|c}
\hline \hline & Number & Percentage \\
\hline $\begin{array}{l}\text { Dewey Classification } \\
\begin{array}{c}\text { Library of Congress } \\
\text { Classification }\end{array}\end{array}$ & 532 & 77.1 \\
$\begin{array}{c}\text { Changing from DC } \\
\text { to LC . }\end{array}$ & 92 & 13.3 \\
$\begin{array}{c}\text { Planning on changing } \\
\text { from DC to LC }\end{array}$ & 58 & 8.4 \\
$\begin{array}{c}\text { Other classifications } \\
\text { Total }\end{array}$ & 4 & .6 \\
\hline
\end{tabular}

tory were willing to reply to the questionnaire. A comprehensive report listing the classification systems used by all junior college libraries would better serve the interests of classification analysis and uniformity and would encourage the recently established national committee on junior college libraries ${ }^{5}$ to deal in the most effective manner with the hitherto ignored issue of classification systems. Obviously the same information would better serve the present and future development of nearly all academic libraries. ${ }^{6}$

Table 2 is a complete listing by state of the results of this classification survey.

Some states-especially California, New York, Pennsylvania, and Wisconsin -show the most reclassification activity to the LC scheme. The states with the highest number of junior colleges using the LC Classification are California (12), Florida (12), New York (16), Pennsylvania (14), and Wisconsin (12). Of those libraries presently reclassifying, nearly all have initiated their change to

5 "Ten-Point Program Outlined for Junior College Libraries," Library Journal, XCI (March 15, 1966), 1377-80.

${ }^{6}$ It appears curious that ACRL, or the Resources and Technical Services Division of ALA have not had the interest to keep an up-to-date record of classification use in the libraries of this country. It is unfortunate that the national professional library organizations that create the standards for library development do not deal with the very important area of library classification. Not until ALA, ACRL, and AAJC decide to put teeth into their published standards (such as the American Chemical Society has done) through strict accreditation requirements that deal not only with minimum standards but also with such matters as classification systems and centralized cataloging will these organizations be really effective. 
Classification Trends in Junior College Libraries / 353

TABLE 2

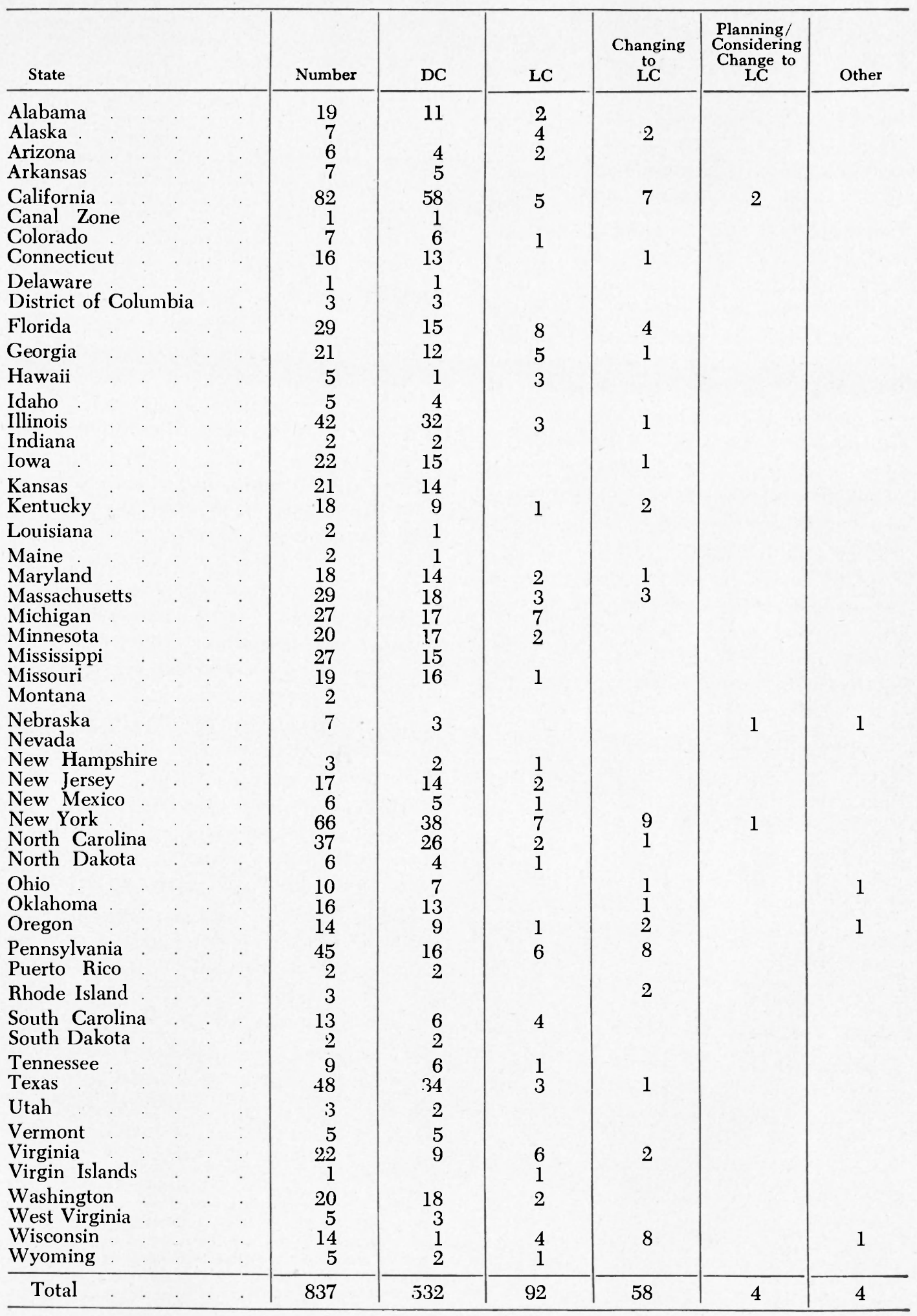


the Library of Congress Classification since 1962.

Since 1960, 225 new junior colleges have been established. Of this number, twenty-one have decided to reclassify their libraries to the LC system. Only fifty-eight of the 690 libraries cooperating reported reclassification projects. This indicates that 36.2 per cent of those libraries involved in reclassification have been founded since 1960 .

Table 3 represents a summary listing of junior college libraries established since 1960 indicating their original library classification scheme.

Of the 159 libraries which started using the Dewey Decimal system, twenty-one later began reclassification to the LC system. Considering this development, the totals of Table 3 are revised in Table 4 to reflect the present classification situation.

Table 5 is a listing of the twenty-one two-year institutions that have changed from Dewey to LC since their founding (1960 or later).

\section{ConClusion ANd Implications}

Although the majority of junior college libraries presently established (and being established) use the Dewey Decimal Classification, the ratio is substantially less now than in 1961. More than thirty-eight per cent of the libraries established since 1960 are using or are reclassifying to the Library of Congress system. This, of course, is an encourag-

TABLE 3

\begin{tabular}{l|l|l|l}
\hline \hline $\begin{array}{c}\text { Year } \\
\text { Established }\end{array}$ & DC & LC & Other \\
\cline { 1 - 2 } 1960. & 23 & 2 & \\
1961. & 23 & 4 & \\
1962. & 23 & 2 & \\
1963. & 24 & 6 & \\
1964. & 18 & 11 & \\
1965. & 30 & 15 & \\
1966. & 18 & 25 & 1 \\
1967. & & & \\
\hline Total & & & \\
$(225=100 \%)$ & $159(71.7 \%)$ & $65(29 \%)$ & $1 \quad(.44 \%)$ \\
\hline
\end{tabular}

TABLE 4

\begin{tabular}{|c|c|c|c|c|}
\hline & & DC & LC & Other \\
\hline $\begin{array}{l}\text { Total } \\
(225=100 \%)\end{array}$ & 138 & $(61.3 \%)$ & $86(38.2 \%)$ & $1 \quad(.44 \%)$ \\
\hline
\end{tabular}

ing development if a national system of library classification and centralized cataloging is desirable. Since libraries have agreed on main entry forms, catalog card format, and information, it seems a natural step to accept a standardized classification system.

It is a bit distressing to contemplate the reclassification projects of the twenty-one two-year institutions, with their extra expense, time, and energy required because of the inadequate original planning, lack of knowledge, and unfamiliarity with the actual nature of available library classification systems. This may be attributed in part to the general inadequacy, by and large, of library school instruction, or perhaps also to complacency and disinterest of the national professional association. One wonders what institutional administrations think of their librarians who recommend reclassification projects only one to four years after the establishment of the library.

Certainly, as Dougherty ${ }^{7}$ points out, reclassification costs are high. Obviously such switching of classification systems in a short period indicates poor library planning that can only denigrate the capabilities of librarians. ${ }^{8}$

Pirie refers to his survey of processing activities in junior college libraries as reminiscent of the labors of Sisyphus.

No matter where or however intensively one's efforts have been directed at recording the myriad practices and procedures of scores of libraries ... [ [one] sees questions

\footnotetext{
7 Richard M. Dougherty, "The Realities of Reclassification," CRL, XXVIII (July 1967), 258-62.

8 It is acknowledged that in some instances the school administration may be public-school oriented and unresponsive to the recommenations of librarians. In this case, a strong statement, or better still, library accreditation standards established by a national association, would force a more responsive relationship.
} 
TABLE 5

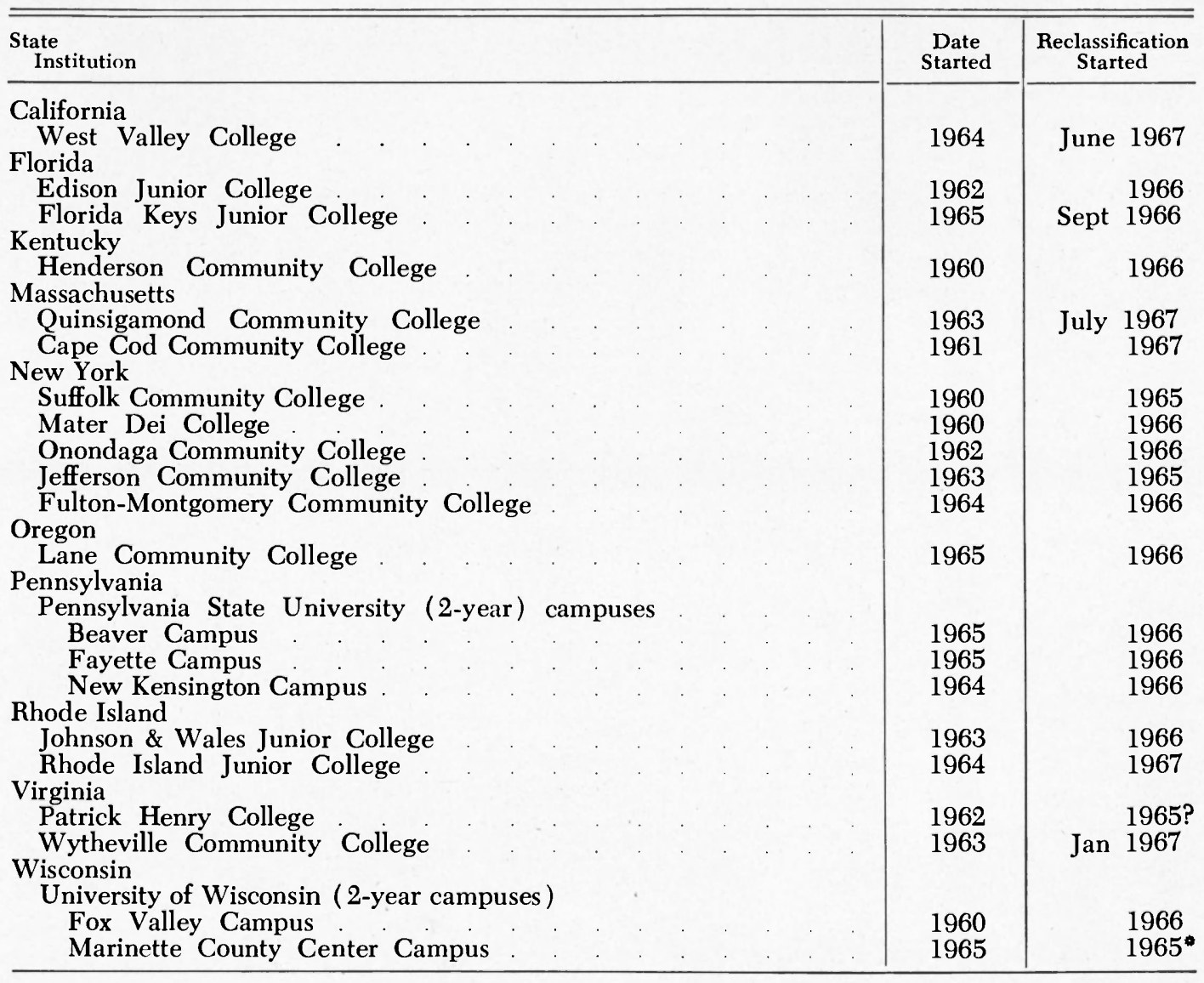

- This library reported that it started using both the DC and the LC Classifications! Now, however, it is using the LC system exclusively.

imperfectly phrased, understood, and answered. The simple truth is that methods of processing in a more or less homogeneous group of libraries are ... bewildering in their variety and ingenious in their meeting of problems in different ways. ${ }^{9}$

Harvey scarcely reassures concerning the quality of librarianship practiced in junior college libraries when he makes such a statement as

... there is almost no other aspect of librarianship where the gap is so great between theory and practice. Junior college libraries are among the poorest kinds of libraries. ${ }^{10}$

\footnotetext{
9 James W. Pirie, "Junior College Library Processing," Library Trends, XIV (October 1965), 166-73.

${ }_{10} \mathrm{John}$ F. Harvey, "The Role of the Junior College Library," CRL, XXVII (May 1966), 227-32.
}

In view of such reports as these it is doubtless unlikely that institutional administrations are always basically to blame for the unwise policy decisions in junior college library operations. The responsibility is primarily that of the librarians in charge.

Shores ${ }^{11}$ indicates that there is a growing trend to independent study and heavier use of library resources in junior college libraries. He emphasizes the central processing trend which will free the librarian from technical routines that can be accomplished more economically. But Shores did not address himself to the classification aspect of centralized proc-

\footnotetext{
11 Louis Shores, "Library Junior College," Junior College Journal, XXXVI (March 1966), 6-9.
} 
essing. Whether a library uses the services of a commercial processing firm or cooperates in centralized processing is, among a number of factors, a matter of available staff and cooperative willingness. Whether it is significantly less costly, however, depends basically on the classification system used. The classification determines the character of the total operation and whether all aspects of a centralized processing operation can be fully exploited for the lowest unit cost per title and volume. ${ }^{12}$

The "Guidelines for Establishing Junior College Libraries"13 do not refer to any preferred classification system or, for that matter, to library classification at all. The only reference is to the operations dependent on such a system. For example:

Unless there is a large staff available to order and process the new books, or unless commercial processing services are used, a neighboring university or public library may be contracted to catalog and process the basic collection. ${ }^{14}$

This statement is good as far as it goes, but some would feel that it leaves unanswered the entire question of classification and its cost of application. The proper application of the Library of Congress Classification can in some cases cut cost nearly in half if standardized procedures and routines are carefully designed and practiced. The librarian should approach LC without the involved trappings associated with the Dewey Decimal Classification in its application. ${ }^{15}$

\footnotetext{
12 According to Theodore Samore in Library Statistics of Colleges and Universities, 1961-62, Part 11, Analytical Report (Washington: USOE, 1964), the percentage of junior college libraries falling below standards increased between 1960 and 1962.

${ }_{13}$ "Guidelines for Establishing Junior College Libraries," CRL, XXIV (November 1963), 501-505.

${ }_{14}$ Ibid., p. 503. A recommendation to accept with caution in lieu of the technical service operations in some university and public libraries.

${ }^{15}$ This is dependent on labor costs, of course, which vary across the country. Large university libraries are sometimes hardly models of careful cost economy and reasonable efficiency in their classification applications, modifications, and technical processing; e.g., Stanford
}

The Seattle area of Washington State, for example, has several two-year community colleges which have been established since 1961. When queried why they had not used the Library of Congress Classification, it was indicated that the Dewey Decimal system was preferred because: (1) it was familiar to the students, and (2) the University of Washington, to which they were feeder schools, used Dewey. Classification costs or economies were scarcely mentioned. Unfortunately for them, the University of Washington library changed to the Library of Congress Classification in January 1967. Now, although at least one of the community college libraries would like to change to LC, the embarrassment of recommending such a project so soon after being established (1964) presents a costly dilemma.

What this could be interpreted by some to mean is that if these libraries had been more familiar with the literature, had analyzed their operations in greater depth, had investigated more fully the available classification alternatives, and had considered more adequately their operational expenses, they would have found it more difficult to use the rationalization of student familiarity as a primary reason in a classification decision. Library literature and library experience seem to indicate that the majority of library users do not care what classification system is used.

Unfortunately, librarians are seldom more than products of their professional training and associations. Although the immediate responsibility is that of the individual librarian, the far-ranging effects are an indictment of the profession.

University and the University of California at Berkeley libraries. Only one example from Stanford, for instance, is their classification of educational materials in a specially devised scheme created a number of years ago. At present there is only one librarian who knows the scheme well enough to apply it to library materials. The University of California at Berkeley has performed some interesting modifications in the LC Classification. Centralized cataloging, apparently, is all things to all libraries. 